\title{
Preface (1990)
}

Renaissance Thought and the Arts, published by Princeton University Press in 1980, has recently gone out of print, and I am grateful to the Press and to Miss Deborah Tegarden for their decision to reprint it, and also to add to it two more papers not included in the previous edition. The paper entitled "Rhetoric in Medieval and Renaissance Culture" was first published by the University of California Press in the volume Renaissance Eloquence (pp. 1-19), edited by James J. Murphy. The paper entitled " 'Creativity' and 'Tradition' " was published by the late Philip P. Wiener in the Journal of the History of Ideas (1983, 44:105-113). I wish to thank the University of California Press for its permission to reprint the first paper, and Professor Donald R. Kelley, editor of the Journal of the History of Ideas, for his permission to reprint the second paper.

The first paper touches on the relation of Renaissance thought to literature and thus is a suitable companion and supplement to chapter 7 , an essay on the language of Italian prose. The importance of rhetoric in Renaissance culture has been emphasized in recent years by many scholars including myself, though the term rhetoric has lately become, as have many others, a magic and much misused word. In my opinion, rhetoric is not a substitute for philosophy, as it is for Valla and some of his recent admirers, but rather another genre and discipline whose importance, from classical antiquity to modern times, I learned long ago to appreciate from my teachers Werner Jaeger and Eduard Norden.

The second, rather short paper has been added to the volume as a kind of appendix. It is less scholarly and more polemical than the rest of the volume, but it is nevertheless pertinent to the relation vii 
that existed between thought and the arts not only during the Renaissance but also at other times, including our own. The paper discusses and criticizes the concept of creativity-a concept that is fairly recent in origin, but that has become a kind of sacred cow in contemporary discourse. The paper originally was commissioned and then rejected by a prestigious national institution that had organized a conference on the topic, but it was later approved by several of my colleagues and friends before being published in the Journal of the History of Ideas. It was subsequently translated into Italian and published in the periodical Il Veltro (1984, 28:17-29). This episode illustrates the fact, not widely admitted, that in a time and place where we do enjoy an almost unlimited freedom from political censorship, another kind of censorship-on ideological grounds or in the service of the goddess Fashion-is secretly being exercised against views that are contrary to prevalent opinions, whatever their validity or their factual or logical basis. I am glad I have this opportunity to make this paper available to the readers of this volume. I am sure that its ironic critique of fashionable views will be disparaged by many readers whose preconceived views it attempts to question, but I hope it will be appreciated by some other, though perhaps fewer, readers.

Although I do not wish to repeat here what I said in the preface to the 1980 edition about the current state of public and academic opinion and its more or less open hostility to all historical scholarship, especially to the study of intellectual history, I am afraid the climate of opinion has not changed for the better during the past ten years; indeed, it may have even changed for the worse. The kind of philosophical, historical, and literary scholarship that is based on the tested methods of philology and on the careful interpretation of original texts and documents-in my view, the only valid basis-is held in contempt and dismissed as "traditional," not only by journalists and popular writers but also by many members of the academic community. They prefer to work from translations and secondary literature, and to use approaches and methods that are reductionist, purely speculative, arbitrary, or even journalistic (but advertised as novel and superior to "traditional" methods) in the name of psychology, new historicism, social history, Marxism, literary criticism or theory, structuralism or deconstructionism, linguistics, analytical philosophy, or hermeneutics; and they often pretend to discover the secret thought of past thinkers and writers that is actually contrary to the straight meaning of their writings. 
In a more recent paper ("Philosophy and Its Historiography," The Journal of Philosophy [1985, 82:618-625]), I called these methods "ventriloquistic," and I am amused to note that a recent practitioner of these methods has tried to give a positive twist to this term. I should also like to call them "extratextual," alluding to the fashionable use of textuality and intertextuality, artificial terms that add nothing except an aura of novelty to the well-known study of sources and influences. All these methods have in common a contempt for what the sources tell us, and a desperate wish to know what the sources do not and cannot tell us. The proponents of these approaches believe that they enrich history by imposing some present ideas on the past, but in fact they impoverish the present and the future by foregoing the chance of enriching modern readers with the additional or alternative ideas and insights that the literature of the past, much of it neglected or forgotten, can offer them. All this is defended with an uncritical kind of relativism that claims that all interpretations are equally valid, without any recognition of the fact that some are valid, some are uncertain or possible, and some are plainly wrong and in contrast with the ascertained facts and with the rules of logical discourse and consistency. Much use is made of what I like to call the argumentum ex ignorantia, that is, the naive or intentional disregard of well-established facts and the setting forth of ideas contrary to the author's opinions-all cheerfully presented under the (correct) assumption that the readers and critics, who are equally ignorant, will not know the difference. Yet I do not wish to exaggerate, and I gladly admit that many excellent studies have been published in recent years, by older and younger scholars alike, who have either ignored the fashionable errors to which I allude or made but minor concessions to them.

I may be too old to understand or appreciate these new trends and their purported value. But I know many younger scholars who share my views, who are hampered in their careers by the political and academic power of the modern charlatans, and cannot afford to say in public what they think about these methods and their proponents. Because I can afford to say what I think, I feel obliged to do so, and to speak on behalf of many younger scholars and of the continuing scholarly tradition, which I hope will survive the current fads and follies as it has survived so many earlier ones. I should like to conclude with this hope, although I see no signs that it will be fulfilled in the foreseeable future. Moreover, unlike many contemporary prophets of doom, who seem to enjoy their dire predictions, 
I, like Cassandra, long to find out that my fears and predictions were groundless.

I should like to dedicate this volume to Hans Sarre in honor of our lifelong friendship, which has survived many good and bad events.

New York, Columbia University

September 21,1989

Paul Oskar Kristeller 